\title{
NIAL ALLOYS FOR TURBINE AIRFOILS
}

\author{
R. Darolia, W. S. Walston and M.V. Nathal*
}

GE Aircraft Engines, Cincinnati, $\mathrm{OH} 45215$

* NASA Lewis Research Center, Cleveland, OH 44135

\section{$\underline{\text { Abstract }}$}

$\mathrm{NiAl}$ alloys offer significant payoffs as structural materials in gas turbine applications due to high melting temperature, low density and high thermal conductivity. Significant improvements in the material properties, processing and design methodology have been achieved. High strength $\mathrm{NiAl}$ alloys which compete with $\mathrm{Ni}$-base superalloys have been developed. NiAl alloys have been successfully manufactured into a variety of turbine components. A high pressure turbine vane has been successfully engine tested. However, limited ductility and toughness as well as poor impact resistance continue to be critical issues which will impede near term production implementation.

\section{Introduction}

One of the greatest challenges currently facing the materials community is the need to develop a new generation of materials to replace nickelbase superalloys in the hot sections of gas turbine engines for aircraft propulsion systems. The present alloys, which have a Ni-base solid solution matrix surrounding $\mathrm{Ni}_{3} \mathrm{Al}$-base precipitates, are currently used at temperatures exceeding $2000^{\circ} \mathrm{F}\left(1100^{\circ} \mathrm{C}\right)$, which is over $80 \%$ of the absolute melting temperature. Since $\mathrm{Ni}_{3} \mathrm{Al}$ melts at $2543^{\circ} \mathrm{F}\left(1395^{\circ} \mathrm{C}\right)$ and $\mathrm{Ni}$ at $2651^{\circ} \mathrm{F}\left(1455^{\circ} \mathrm{C}\right)$, it is clear that significantly higher operating temperatures, with the attendant improvements in efficiency and thrustto-weight ratio, can only be attained by the development of an entirely new higher melting temperature material system. This problem is a primary reason for the high level of interest in high temperature intermetallic compounds.

NiAl offers many advantages, 1) density of $0.21 \mathrm{lb} / \mathrm{in}^{3}\left(5.9 \mathrm{~g} / \mathrm{cm}^{3}\right)$, approximately $2 / 3$ of nickel-base superalloys, 2) thermal conductivity which is 4 to 8 times those of nickel-base superalloys, 3) high melting temperature $\left(1638^{\circ} \mathrm{C}\right)$ which is approximately $450^{\circ} \mathrm{F}\left(250^{\circ} \mathrm{C}\right)$ higher than nickel-base superalloys, 4) excellent oxidation resistance, 5) simple ordered body centered cubic derivative $(\mathrm{CsCl})$ crystal structure and small slip vectors for potentially easier plastic deformation compared to many other intermetallic compounds, 6) lower ductile-to-brittle transition Superalloys 1996

Edited by R. D. Kissinger, D. J. Deye, D. L. Anton,

A. D. Cetel, M. V. Nathal, T. M. Pollock, and D. A. Woodford

The Minerals, Metals \& Materials Society, 1996 temperature relative to other intermetallics and 7) relatively easy processability by conventional melting, powder, and machining techniques.

Many recent reviews provide additional information on the physical and mechanical properties of NiAl. ${ }^{[1-6]}$ The purpose of this paper is to build on these reviews while emphasizing more recent results that pertain to actual application of $\mathrm{NiAl}$ in jet engines. We will emphasize single crystal NiAl since this technology has come the farthest towards this goal. Some alternatives to single crystals will also be addressed.

\section{General Characteristics of $\mathrm{NiAl}$}

$\mathrm{NiAl}$ melts congruently at $=2980^{\circ} \mathrm{F}\left(1638^{\circ} \mathrm{C}\right)$ and has a wide single phase field which extends from 45 to 60 at.\% $\mathrm{Ni}$. This feature is different from the majority of other intermetallic compounds which are either line compounds or have a very narrow phase field. The ordered hcc B2 ( $\mathrm{CsCl}$ prototype) crystal structure of NiAl consists of two interpenetrating primitive cubic cells, where $\mathrm{Al}$ atoms occupy the cube corners of one sublattice and $\mathrm{Ni}$ atoms occupy the cube corners of the second sublattice. The ordering energy is believed to be very high which makes dislocation mobility rather difficult. The crystal structure of the strengthening Heusler phase, $\mathrm{Ni}_{2} \mathrm{AlTi}$, represents a further ordering of the $\mathrm{B} 2$ structure.

\section{Single Crystal NiAl}

A relatively large effort has been ongoing at GE Aircraft Engines since the late 1980 's on the development of single crystal NiAl alloys. Initial efforts successfully improved the room temperature tensile ductility of relatively weak $\mathrm{NiAl}$ alloys, while more recent efforts have been focused on alloys with improved high temperature strength. The following sections will review the physical and mechanical properties of single crystal $\mathrm{NiAl}$ alloys and recent successes in utilizing these alloys in turbine airfoil applications. 


\section{Physical Properties}

One of the primary advantages of $\mathrm{NiAl}$ alloys is lower density compared to superalloys. The density of stoichiometric NiAl is 0.21 $\mathrm{lb} / \mathrm{in}^{3}\left(5.90 \mathrm{~g} / \mathrm{cm}^{3}\right)$ compared to about $0.31 \mathrm{lb} / \mathrm{in}^{3}\left(8.6 \mathrm{~g} / \mathrm{cm}^{3}\right)$ for many first generation single crystal superalloys. Because the alloying additions made to $\mathrm{NiAl}$ tend to be less than 5 at.\%, the effect on density is minor as shown in Figure 1. Current single crystal NiAl alloys of interest have a density of approximately $0.22 \mathrm{lb} / \mathrm{in}^{3}\left(6.0 \mathrm{~g} / \mathrm{cm}^{3}\right)$, which offers a $30 \%$ reduction compared to single crystal superalloys.

The coefficient of thermal expansion (CTE) is important for structural applications since thermal stresses depend directly on the magnitude of the CTE. The CTE of NiAl is comparable to that typical for Ni-base superalloys, as shown in Figure 2. The elastic modulus of single crystal NiAl is highly anisotropic; the modulus values are around 13.8, 26.8 and $39.2 \times 10^{6} \mathrm{Msi}$. for the $\langle 100\rangle,\langle 110\rangle$ and $\langle 111\rangle$ orientations, respectively. ${ }^{[7,8]}$ Stoichiometry and minor alloying additions have little influence on both the elastic modulus and the CTE. ${ }^{\text {[7] }}$

Thernal conductivity is another inportant property in turbine airfoil design because a high thermal conductivity can create a more uniform tempcrature distribution in a turbine airfoil and reduce the "life limiting" hot spots. The thermal conductivity of binary NiAl is approximately $5 \mathrm{X}$ that of single crystal superalloys at $1000^{\circ} \mathrm{C}$. Figure 3 shows the effect of alloying additions on the thermal conductivity of $\mathrm{NiAl}{ }^{[7]}$ While alloying additions decrease the thermal conductivity of binary NiAl, a $3 \mathrm{X}$ benefit is still maintained over single crystal superalloys at $1000^{\circ} \mathrm{C}$.

\section{Mechanical Properties}

\section{Tensile Ductility}

For binary NiAl, $<001>$ oriented "hard" single crystals fail at room temperature after only elastic deformation, while other ("soft") orientations, such as $\langle 110\rangle$ and $\langle 111\rangle$, usually possess up to $2 \%$ plastic

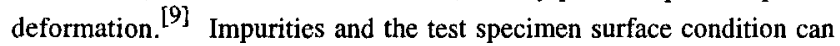
have a dramatic effect on measured ductility. ${ }^{[10,11]}$ Potential factors limiting ductility in single crystals include inadequate dislocation sources, low dislocation mobility, inhomogeneous slip, and low fracture stress. Each of these have been postulated to explain the brittle failure of NiAl single crystals.

Results of a large alloy development effort at GE Aircraft Engines have shown that microalloying with $\mathrm{Fe}, \mathrm{Ga}$, and Mo can significantly improve the room temperature (RT) tensile ductility of NiAl single crystals tested along a $\langle 110\rangle$ direction (soft orientation), increasing the failure strain from a typical value of $1 \%$ for stoichiometric $\mathrm{NiAl}$ to as high as $6 \%$ for $\mathrm{NiAl}+0.25 \% \mathrm{Fe}^{[1,12]}$ A subsequent study was conducted to determinc the source of scatter in the room temperature tensile ductility of a NiAl $+0.1 \% \mathrm{Fe}$ alloy. ${ }^{[10]} \mathrm{RT}$ tensile plastic elongations varied from about $0.5 \%$ for as-ground specimens to about $8 \%$ for electropolished specimens when the grinding marks were completely removed, as shown in Figure 4. The surface effect is related to high notch sensitivity of NiAl due to low ductility and low fracture toughness.

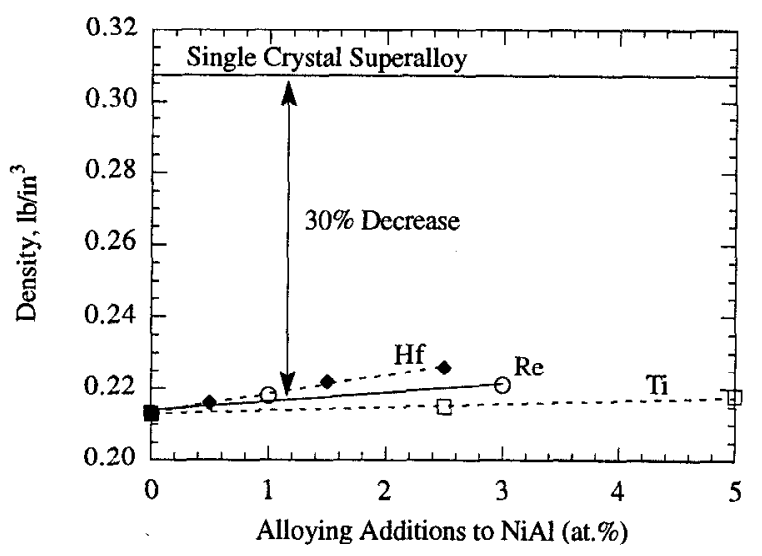

Figure 1. Measured density of NiAl as function of alloying content.

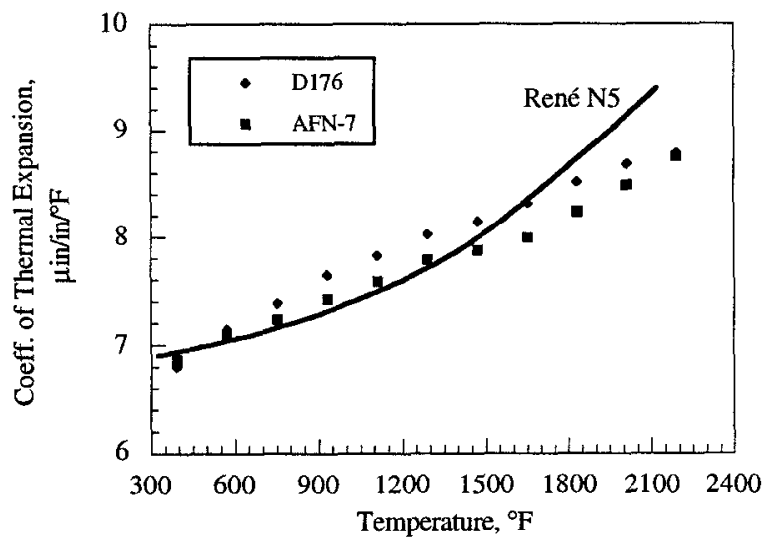

Figure 2. The coefficient of thermal expansion of two NiAl alloys compared to single crystal superalloy René N5.

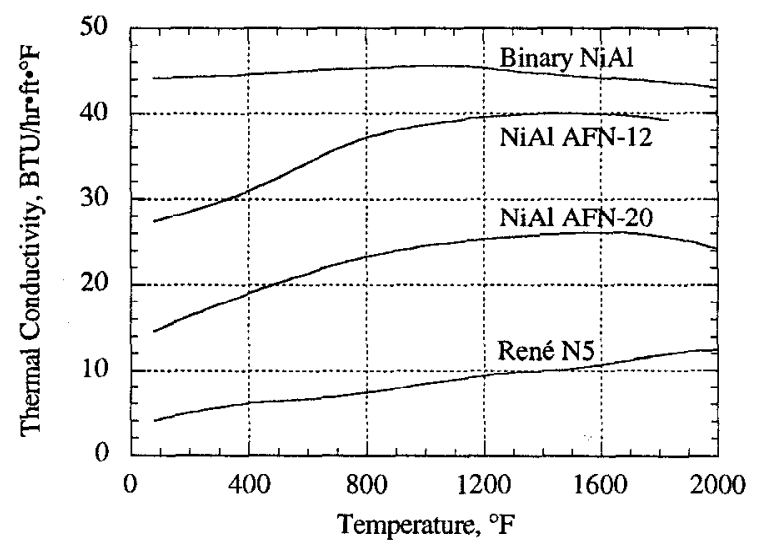

Figure 3. The thermal conductivity of three $\mathrm{NiAl}$ alloys as a function of temperature. Data for a typical single crystal Ni-base superalloy is provided for comparison. 
The ductile-to-brittle transition temperature (DBTT) for "soft" binary $\mathrm{NiAl}$ crystals is $400^{\circ} \mathrm{F}\left(200^{\circ} \mathrm{C}\right)$, while "hard" crystals become ductile just below $750^{\circ} \mathrm{F}\left(400^{\circ} \mathrm{C}\right) .{ }^{[9]}$ Binary NiAl single crystals become very ductile above the DBTT, and both "hard" and "soft" crystals exhibit more than $20 \%$ elongation at $750^{\circ} \mathrm{F}\left(400^{\circ} \mathrm{C}\right) .{ }^{[9,13]}$ However, NiAl single crystal alloys which possess reasonably good high temperature strengths are much less ductile than binary NiAl, have high DBTT's which increase as the strength is increased, and possess low fracture toughness values. Figure 5 shows ductility as a function of temperature typical of strengthened NiAl alloys. ${ }^{[4]}$ In "strong" NiAl alloys, even with minor alloying additions, the DBTT can increase beyond $1470^{\circ} \mathrm{F}\left(800^{\circ} \mathrm{C}\right)$ for the $\langle 110\rangle$ orientation, as shown in Figure 5. Of significant scientific interest is the shift in orientation dependence of the DBTT. In binary $\mathrm{NiAl}$, the $<110>$ has a DBTT about $350^{\circ} \mathrm{F}\left(200^{\circ} \mathrm{C}\right)$ lower than the $\left.<001\right\rangle$ orientation, however, in strong NiAl alloys, this behavior is reversed. ${ }^{[14]}$

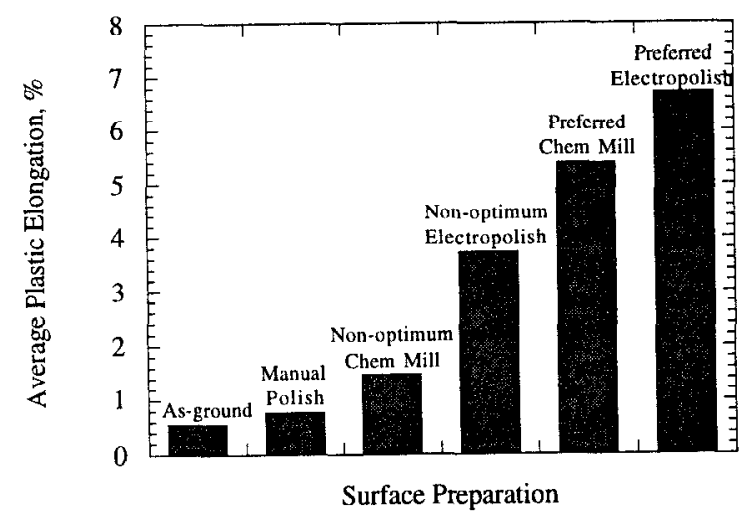

Figure 4. The effect of surface finish on the RT ductility of a Fecontaining NiAl alloy.

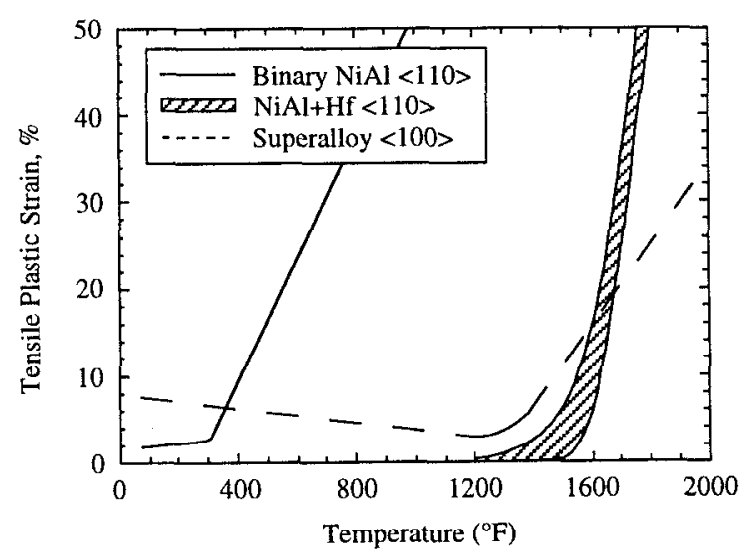

Figure 5. Tensile ductility of strengthened $\mathrm{NiAl}$ single crystal alloys as a function of temperature compared to the ductility of binary $\mathrm{NiAl}$ and a typical Ni-base superalloy.

\section{Eracture Toughness}

Like most intermetallic compounds, the fracture toughness of binary $\mathrm{NiAl}$ is low. The fracture toughness is dependent on the heat treatment, crystallographic direction with respect to loading direction, and the orientation and geometry of the notch. Typically a value of $8 \mathrm{ksi} \sqrt{\mathrm{in}}$ is obtained from a specimen oriented in the $\langle 100\rangle$ direction in a four point bend test with a single edge through notch, whereas a value of $4 \mathrm{ksi} \sqrt{\text { in }}$ is obtained in the $\langle 110\rangle$ orientation. ${ }^{[15,16]}$ Recently, ${ }^{[17]}$ the fracture toughness in the $\langle 110\rangle$ oriented single crystal NiAl was shown to be improved by minimizing strain-age embrittlement by fast cooling through the temperature range $400^{\circ} \mathrm{C}-20^{\circ} \mathrm{C}$. Fracture toughness in the range $13-17 \mathrm{ksi} \sqrt{\text { in }}$ was obtained in $\langle 110\rangle$ oriented double cantilever beam toughness specimens. Additions of $\mathrm{Fe}$ and $\mathrm{Ga}$, which increased the RT ductility of $<110\rangle$ single crystals, improved the RT fracture toughness by up to $20 \% .^{[13]}$ However, in high strength alloys

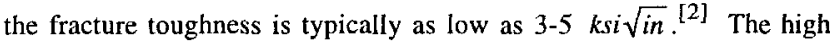
DBTT and low fracture toughness of the strengthened NiAl single crystal alloys remain an issue which must be resolved through further alloy development as well as innovative designs.

\section{Ductility and Fracture Toughness Requirements}

An exact level of ductility or toughness requirement has not been established in the design of a turbine blade or vane. Very limited experience exists on components made out of materials with low ductility and fracture toughness. However, some amount of ductility or toughness is desirable for processibility, handling and assembly, component reliability and attachment to a superalloy part. For example, plastic deformation will be helpful in relieving high contact stresses between the airfoil and the turbine disk in the attachment region, especially at radii in the dovetail. A fraction of one percent room temperature plastic elongation is probably sufficient for relieving point loading. Also, since the NiAl part will be attached to a Ni-base superalloy part which could have different thermal expansion characteristics, up to about $2 \%$ plastic elongation (based on typical thermal expansion mismatch between $\mathrm{NiAl}$ and $\mathrm{Ni}$-base superalloy and temperatures of use) may be required to avoid premature fracture under thermal transient conditions. Additionally, innovative designs and attachment concepts are required. Ni-base superalloys typically have a room temperature toughness of $40-50 \mathrm{ksi} \sqrt{\mathrm{in}}$. A new material must have a minimum toughness in the range of $15-20 \mathrm{ksi} \sqrt{\mathrm{in}}$, based on typical defect sizes and to obtain acceptance in the design community.

\section{Implications of a Low Toughness Material for Design}

Due to its low fracture toughness, NiAl has a low defect tolerance. Internal defects, such as inclusions and porosity, may originate from processing, while machining may introduce defects such as scratches, grinding marks, and cracks. Based on typical stresses encountered and the fracture toughness of the NiAl alloys, the defect size needs to be controlled to no higher than $25 \mu \mathrm{m}$. In addition to reducing the defect size, design methodologies which can account for the size, type, and location of defects likely to be encountered in the part need to be established. The design should consider allowable stresses based on the fracture toughness and the typical defect size likely to be introduced in the part. Also, a design methodology based on a probabilistic, and not a deterministic, approach needs to be developed. This type of approach is being emphasized in a current Air Force program being conducted at GE Aircraft Engines and NASA Lewis Research Center. ${ }^{[18]}$ The design data base should include not only properties determined on laboratory specimens and sub components, but also properties from 
component testing in a variety of simulated conditions on parts with actual configurations. These parts should be made utilizing the same processes which will be used in production to reliably reproduce the defect distributions of the manufactured hardware. The design of the components should utilize the minimum properties possible, and not the average properties. Design safety margins will depend on the criticality of the part in the total system, and allowed safety factors are likely to be greater than for ductile metals until an experience base for alloys with limited ductility and damage tolerance is established. The long range goal should be to improve fracture toughness as well as produce cleaner material. These design considerations should be applicable to all intermetallic components.

\section{High Temperature Strength}

The high temperature strength of NiAl has been improved by solidsolution strengthening, precipitation strengthening, dispersion strengthening and by elimination of grain boundaries by the single crystal processing route.

Elements such as $\mathrm{Co}, \mathrm{Fe}$, and $\mathrm{Ti}$ have a high solubility in $\mathrm{NiAl}$, and can provide significant solid solution strengthening. ${ }^{[19-21]}$ Solid solution strengthening can be significant even at low level additions of the ternary element. especially with addition of group IVB and VB elements such as Ti, Hf, Zr, V, and Ta. For example, an addition of $0.2 \% \mathrm{Hf}$ to $\mathrm{NiAl}$ increases the room-temperature tensile strength of a $<110>$ oriented specimen from a typical value of $210 \mathrm{MPa}$ for stoichiometric $\mathrm{NiAl}$ to $600 \mathrm{MPa} .{ }^{[12]}$ Elements such as $\mathrm{Cr}$, Mo and Re have a low solubility $(<1 \%)$ in NiAl. When added beyond their solubility limit, these elements precipitate a disordered $b c c$ phase, which strengthens NiAl.

Additions of group IVB or VB elements beyond their solubility limits in NiAl produce several ternary intermetallic compounds, including the $\mathrm{L} 2_{1}$ Heusler $\left(\boldsymbol{B}^{\prime}, \mathrm{Ni}_{2} \mathrm{AlX}\right)$ phase and the primitive hexagonal Laves phase (NiAlX), where $\mathrm{X}$ can be $\mathrm{Hf}, \mathrm{Ti}, \mathrm{Ta}, \mathrm{Zr}$ and $\mathrm{Nb}$. These phases contribute significantly to the strengthening of the NiAl alloys. ${ }^{[19,22,23]}$ The close relationship between the $\mathrm{B} 2$ and $\mathrm{L} 2{ }_{1}$ crystal structures results in coherent or semi-coherent $B^{\prime}$ precipitates. Si pick up (6001000 wppm) from the mold materials during single crystal processing also results in several possible precipitate microstructures that are not implied from the ternary phase $\mathrm{Ni}$-Al-X phase diagrams. Both $\mathrm{Ni}_{16} \mathrm{X}_{6} \mathrm{Si}_{7}$ (G-phase) and $\mathrm{NiXSi}$ can form in addition to the expected Heusler and Laves phases. The presence or absence of these various precipitates can change after heat treatment or creep exposure, depending on the level of $\mathrm{Si}$ in the alloy. All of these phases tend to be very fine in size and resistant to coarsening, and appear to contribute to the strength of these alloys. ${ }^{[24-26]}$

By combining several of the strengthening mechanisms mentioned above, significant improvements in high temperature strength of single crystal $\mathrm{NiAl}$ alloys have been made such that their strengths equal single crystal superalloy René N4 strength levels (Figure 6). In this figure, tensile rupture stress for single crystal NiAl alloys is plotted against the Larson-Miller parameter. While there is a strong orientation dependence on strength in the weaker $\mathrm{NiAl}$ alloys, the stronger $\mathrm{NiAl}$ alloys show little orientation effect. The $\langle 110\rangle$ oriented specimens were slightly stronger than the $<001>$ oriented specimens, although this difference was not statistically significant. Accounting for the lower density of $\mathrm{NiAl}$, these $\mathrm{NiAl}$ alloys are viable replacements for the stateof-the art single crystal Ni-base superalloys, as shown in Figure 7. Figure 8 shows a comparison of the rupture life of several $\mathrm{NiAl}$ alloys at $982^{\circ} \mathrm{C}$. A SEM micrograph showing the $B+B^{\prime}$ microstructure of one of the high strength alloys is presented in Figure 9.

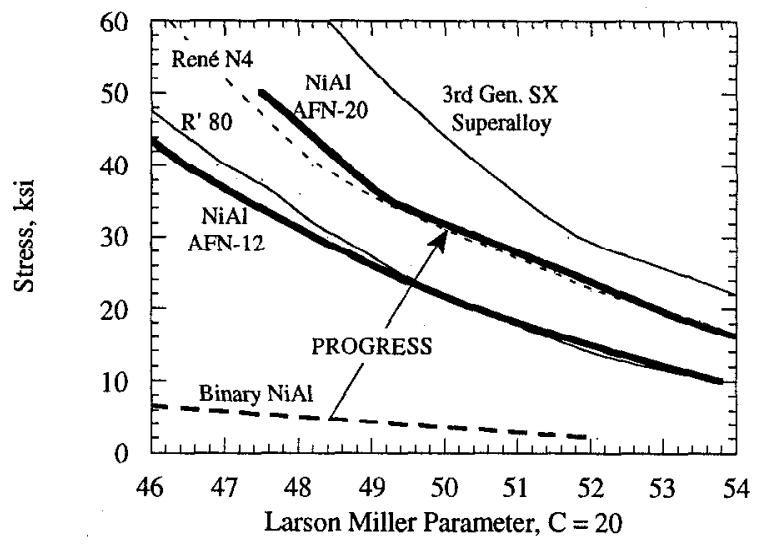

Figure 6. The rupture strength of NiAl alloys is equivalent to the first generation single crystal superalloy René N4.

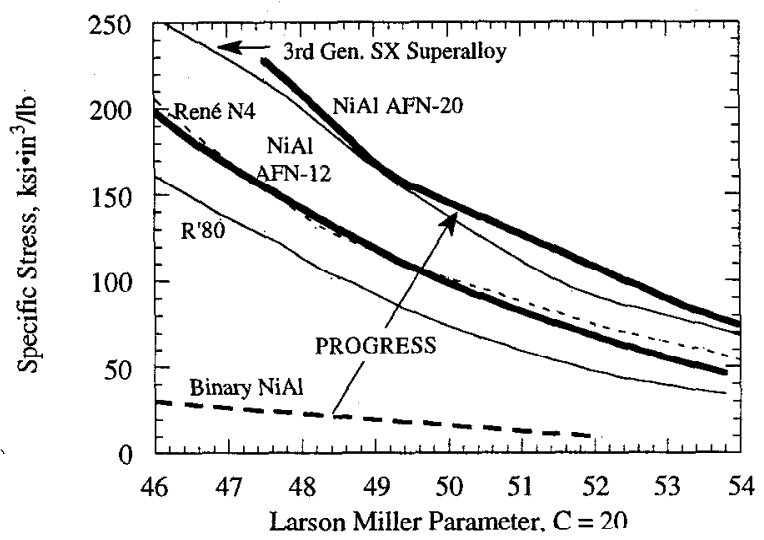

Figure 7. The density compensated rupture strength of NiAl alloys is equivalent to the latest single crystal superalloy René N6.

\section{Creep Behavior}

The creep resistance of the NiAl alloys has followed the improvements in their high temperature tensile and stress rupture strengths. Significant improvement in creep resistance is obtained with the addition of $\beta^{\prime}$ forming elements to NiAl. Figure 10 shows the progress made in creep strength over the last several years. While the binary $\mathrm{NiAl}$ (D5) is very weak, ${ }^{[27]}$ a small addition of Hf (D117) can dramatically improve the strength. Further alloying modifications (AFN-20) result in creep strength nearly equivalent to first generation single crystal superalloys. The creep exponents for the $\mathrm{NiAl}$ alloys appear to be similar to the superalloys, which implies that the precipitates are contributing to strengthening in much the same manner as the $\gamma^{\prime}$ phase in the $\gamma / \gamma^{\prime}$ microstructure of the superalloy. 


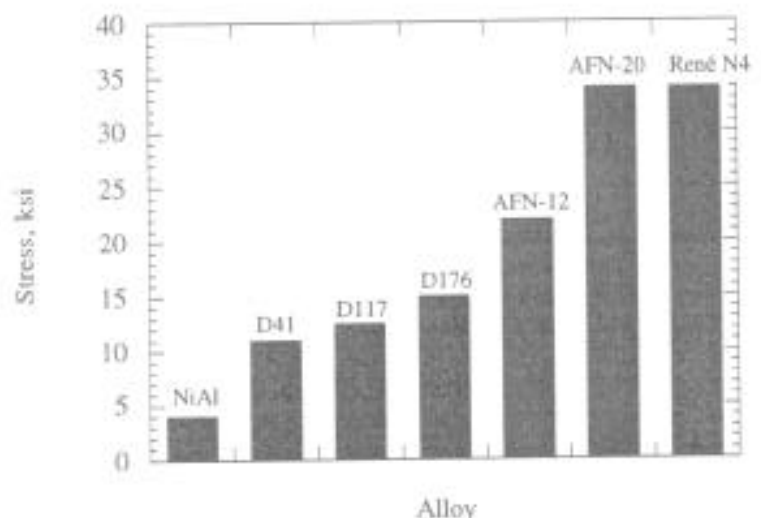

Figure 8. Stress level for $100 \mathrm{hr}$ rupture life at $1800^{\circ} \mathrm{F}\left(982^{\circ} \mathrm{C}\right)$ for various $\mathrm{NiAl}$ alloys

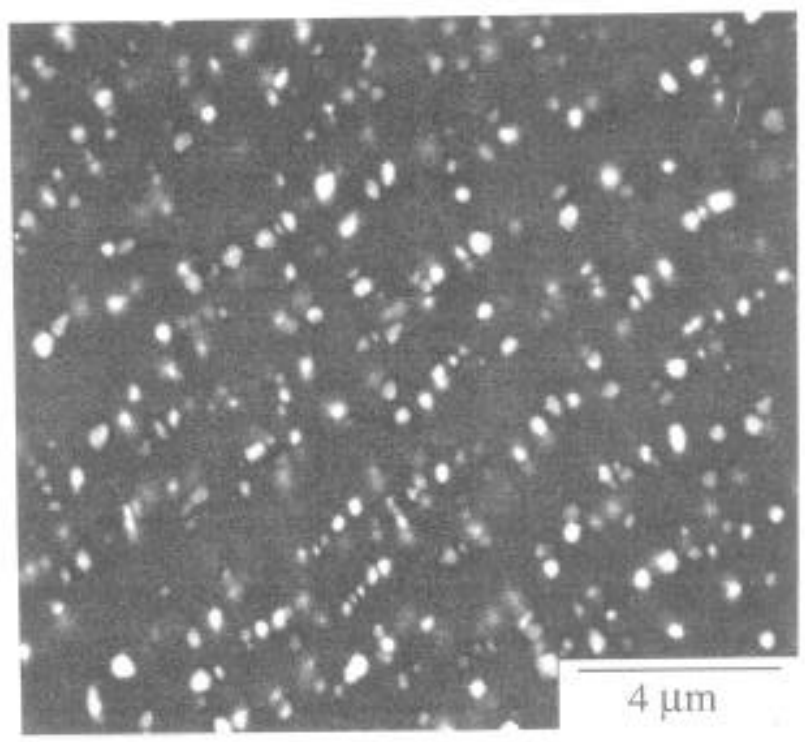

Figure 9. $B+B^{*}$ microstructure typical of the strengthened NiAl alloys.

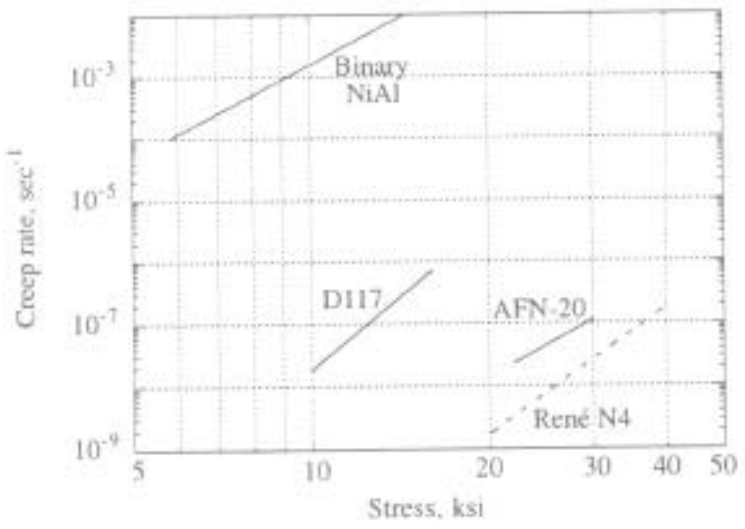

Figure $10,1800^{\circ} \mathrm{F}$ creep strength of NiAl alloys D5, D117 and AFN-20 compared to first generation single crystal superalloy René $\mathrm{N} 4$

\section{Eatigue Behavior}

Low eycle and high cycle fatigue tests have been conducted on several strengthened single crystal NiAl alloys. LCF tests were run in strain control at $1200^{\circ} \mathrm{F}\left(649^{\circ} \mathrm{C}\right)$ and $2000^{\circ} \mathrm{F}\left(1093^{\circ} \mathrm{C}\right)$ at an A ratio of infinity, and HCF tests were run in load control at $2000^{\circ} \mathrm{F}\left(1093^{\circ} \mathrm{C}\right)$ with an $\mathrm{A}$ ratio of 0.25 and 1.0. Compared to Ni-base superalloys, the L.CF behavior of the strengthened NiAl alloys was found to be excellent. For example, at $1200^{\circ} \mathrm{F}$, the fatigue lives were greater than even the third generation single crystal superalloys. The fatigue life was about 125,000 cycles at $586 \mathrm{MPa}$. $1200^{\circ} \mathrm{F}$ is about $200^{\circ} \mathrm{F}$ below the DBTT of the alloy in this orientution, and was chosen to determine if the alloy would have poor fatigue behavior below its DBTT due to lack of ductility and poor defect tolerance. The LCF behavior of NiAl alloy AFN- 12 at $1093^{\circ} \mathrm{C}$ is shown in Figure $1 \mathrm{I}$ and compared to Renć 80 and Rene N4. While the rupture strength of AFN-12 is only equivalent to René 80, the fatigue strength is comparable to René N4. The HCF behavior of NiAl alloy AFN-12 also compares very favorably to single crystal superalloys. Figure 12 shows the $2000^{\circ} \mathrm{F}\left(1093^{\circ} \mathrm{C}\right), \mathrm{A}=1$, HCF strength of AFN-12 compared to René N4. The NiAl specimens were brazed to superalloy threads, and Figure 12 shows that one of the specimens failed at the braze joint.

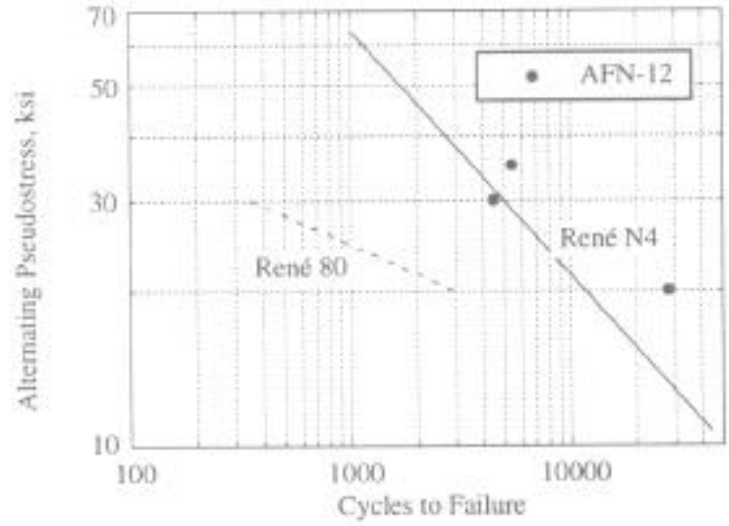

Figure 11, LCF behavior of $\mathrm{NiAl}$ alloy $\mathrm{AFN}-12$ at $20060^{\circ} \mathrm{F}\left(1093^{\circ} \mathrm{C}\right)$. $\mathrm{A}=\infty$ compared to René 80 and René N4

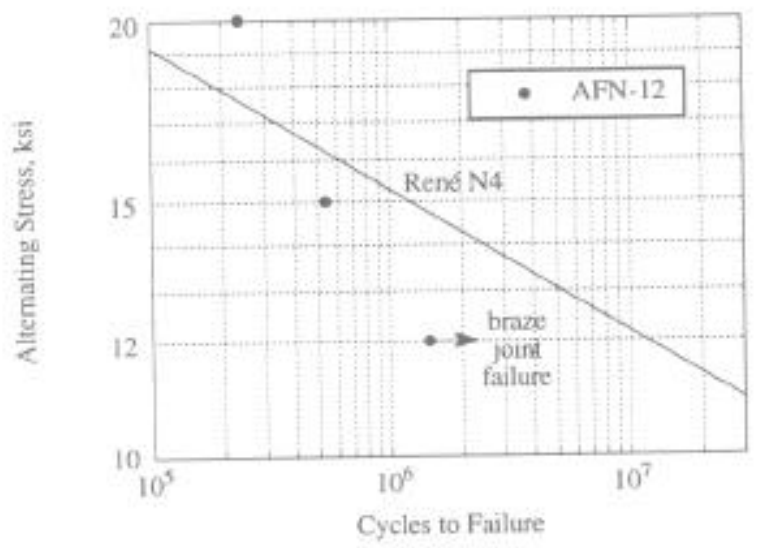

Figure 12. HCF behavior of NiAl alloy $\mathrm{AFN}-12$ at $2000^{\circ} \mathrm{F}\left(1093^{\circ} \mathrm{C}\right)$, $\mathrm{A}=1$ compared to René N4. 


\section{Impact Resistance}

A series of ballistic impact tests on NiAl panels was conducted to evaluate high strain sensitivity of the strengthened NiAl alloys. These panels were tested as a function of thickness, temperature, angle of impact, impact velocity, impacting particle size and particle strength. Panels were tested in the uncoated condition, and with a 5 mil thick thermal barrier coating ( $\mathrm{TBC}$ ). To better simulate engine conditions, paneis were also impacted at $1700-1800^{\circ} \mathrm{F}$ with $\mathrm{Al}$ balls of varying room temperature yield strengths to simulate superalloys at elevated temperatures.

Testing conditions were varied to simulate impact speed conditions for blades, vanes and combustor shingles. The test data are schematically summarized in Figure 13. Based on dozens of tests, it was concluded that the NiAl panels would not survive the impact velocities (>1000 $\mathrm{ft} / \mathrm{sec}$ ) typically encountered by high pressure turbine blades. However, at lower impact speeds simulative of vane conditions ( $450 \mathrm{ft} / \mathrm{sec}$ ). NiAl alloys performed well with no damage under most conditions. Additionally, tests with much thicker (20 to 40 mil) plasma sprayed TBC coatings simulative of combustor applications, showed that NiAl is a viable candidate for combustor applications with no damage under combustor impact conditions. These tesis have confirmed the vulnerability of $\mathrm{NiAl}$ alloys to high strain rate impact events, especially for blade applications. Further material and design innovations will be required to make single crystal $\mathrm{NiAl}$ a viable blade material.

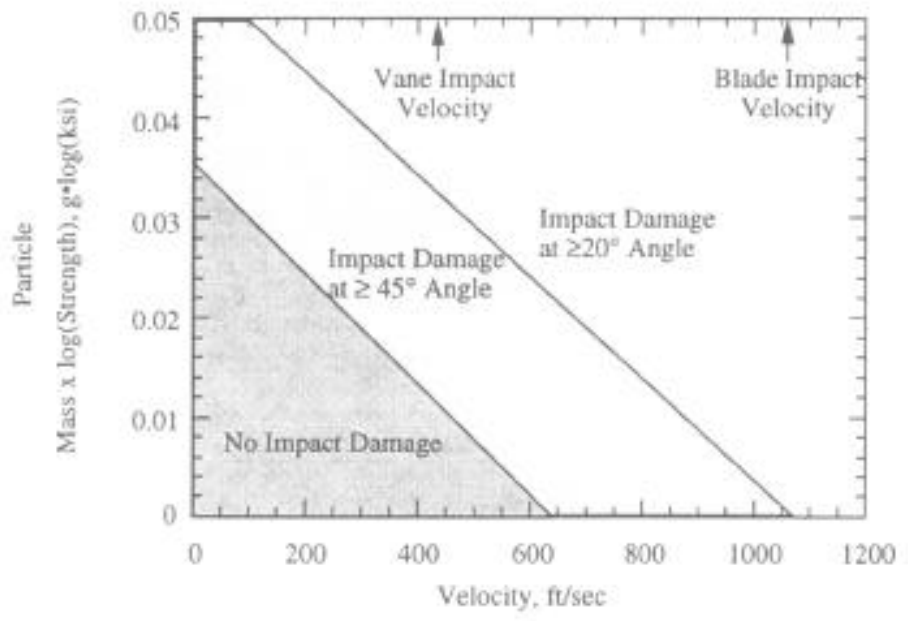

Figure 13. Summary of ballistic impact behavior of a strengthened NiAl alloy. Tests were conducted on thin wall panels at $1800^{\circ} \mathrm{F}$.

\section{Processing and Manufacturing}

Due to the high ductility and low flow stress of binary NiAl above $750^{\circ} \mathrm{F}$ $\left(400^{\circ} \mathrm{C}\right)$, conventional thermomechanical processing, such as hot isostatic pressing (HIP) and hot pressing of powder compacts, extrusion, and swaging have been successfully applied to NiAl. However, directional solidification and single crystal growth are currently the preferred processing routes for turbine blades and vanes, since the elimination of grain boundaries is necessary to obtain adequate high temperature creep strength. Single crystal bars of NiAl alloys up to 1.5 in. $x \quad 1.5$ in, in cross section have been produced by a modified Bridgman technique. ${ }^{[1,2,28]}$ Containerless float zone processes, Czochralski crystal growth, and modified edge-defined, film-fed growth have also successfully produced $\mathrm{NiAl}$ single crystals. ${ }^{[28]}$

The major challenge in producing single crystal blades of NiAl alloys is the high processing temperature, which is roughly $600^{\circ} \mathrm{F}\left(300^{\circ} \mathrm{C}\right)$ higher than the most advanced Ni-base superalloys. The higher processing temperatures approach the limits of existing ceramic mold and core materials in terms of structural capability and reactivity with molten NiAl. While large NiAl single crystal bars and airfoil shapes can be made using the modified Bridgman process, casting of hollow, thin-wall structures has been demonstrated only with tubes. The limited lowtemperature plasticity of most NiAl alloys, combined with the strains generated when the metal shrinks around the ceramic core during cooling from the casting temperature, results in severe cracking of the casting.

The current approach to make a turbine blade consists of casting a solid near net-shape airfoil which can be split into two halves to machine the internal cooling cavities, channels and slots. The two halves are then bonded together by an activated diffusion bonding process. Finally, the 'fabricated' airfoil is finish machined which includes drilling of cooling holes. Blade castings sufficiently large enough to fabricate airfoils for advanced engines have been produced. Examples of a large single crystal NiAl casting are shown in Figure 14.

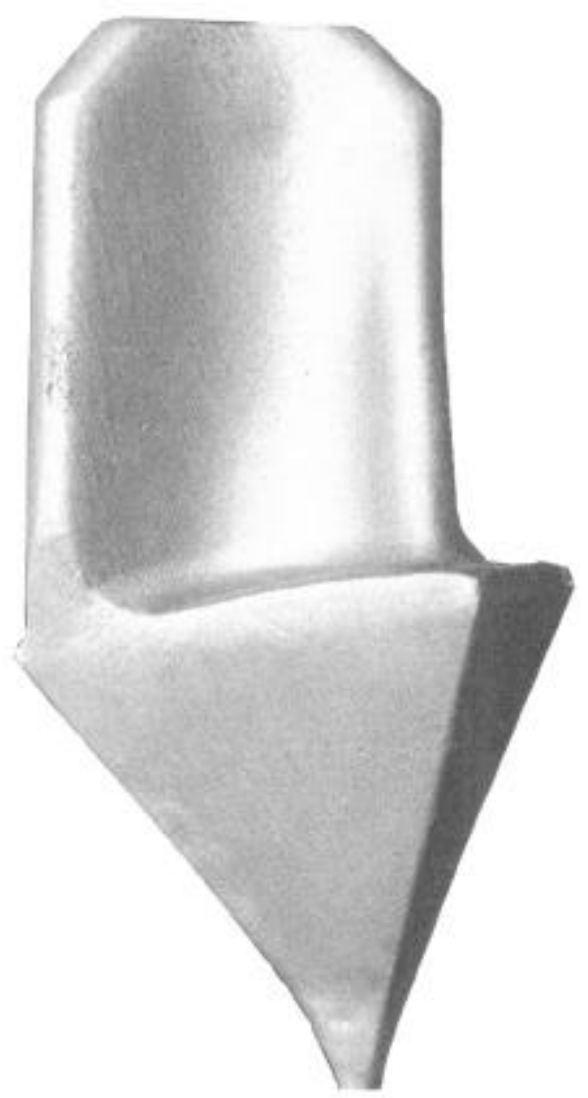

Figure 14. Single crystal NiAl castings of a large HPT blade shape. 
A need to join NiAl to itself or to a superalloy exists in order to overcome processing difficulties or to add a superalloy's toughness to a NiAl component. For example, a NiAl airfoil bonded to a superalloy dovetail could alleviate much of the ductility requirements associated with the root attachment, although at a weight penalty. To this end, several techniques based on diffusion bonding, transient liquid phase processes and brazing have been evaluated ${ }^{[29,30]}$ Self generated filler metal produced by high temperature vacum annealing of NiAl has also been utilized to bond NiAl to itself and to superalloys with positive initial

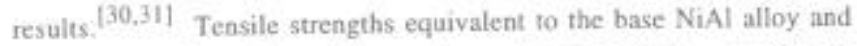
failure away from the weld zone have been achieved. Bumer rig thermal shock test results, however, have been mixed. Further development in this area is required.
NiAl alloys have been successfully manufactured into a variety of turbine components: Many conventional and non-conventional lowstress material removal techniques (grinding. electro-discharge machining (EDM), electrochemical machining, chemical milling. electrostream drilling. ultrasonic machining, and abrasive waterjet) have been successfully used on NiAl alloys. High pressure turbine (HPT) vane airfoils have been machined from single crystal NiAl slabs using EDM. The recrystallized layer generated by the EDM process was removed by subsequent chemical milling. Several processes were demonstrated on this component including 14 mil cooling holes, trailing edge slots, brazing and thermal barrier coating (TBC) application. Figure 15 shows several of these airfoils prior to assembly as a HPT nozzle. Figure 16 shows one of the HPT nozzles that was recently successfully engine tested.

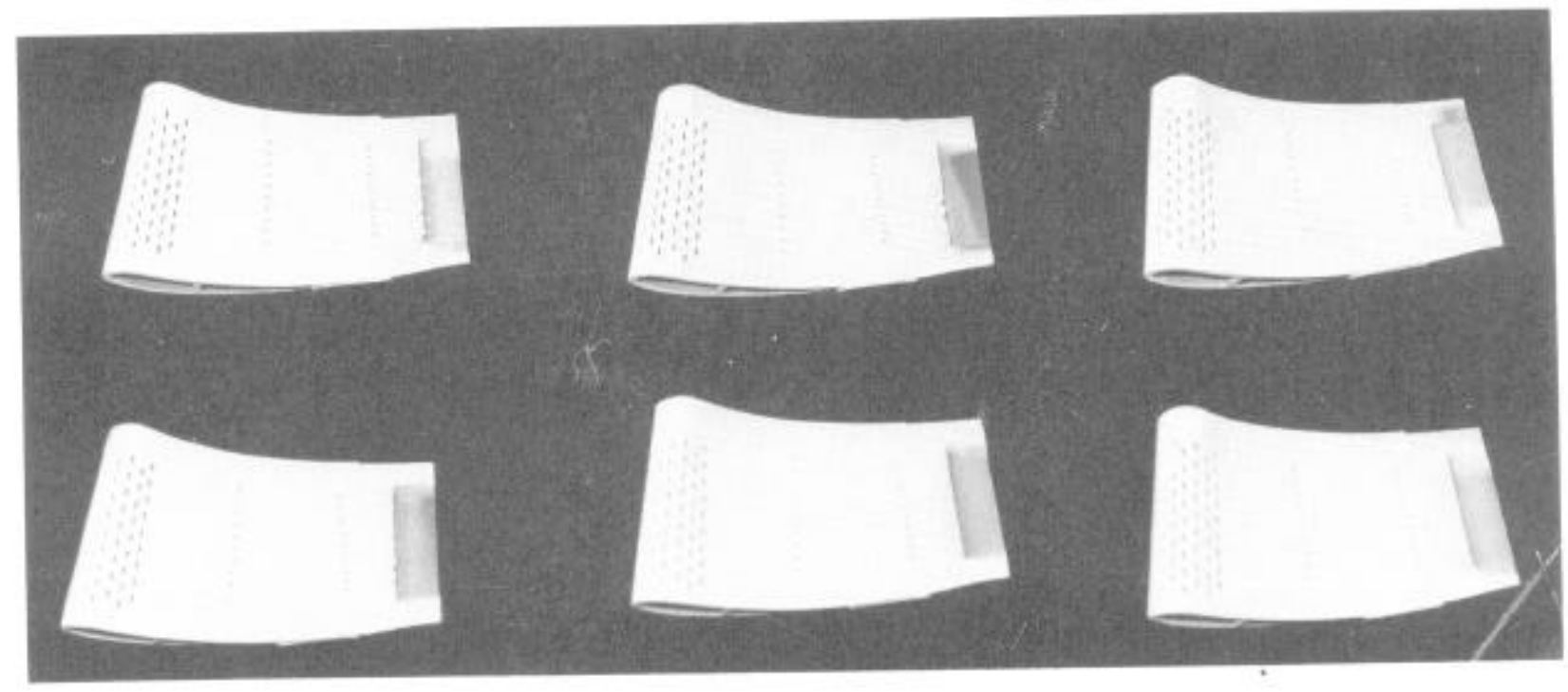

Figure 15. Singie crystal NiAl alloy HPT vanes prior to nozzle assembly.

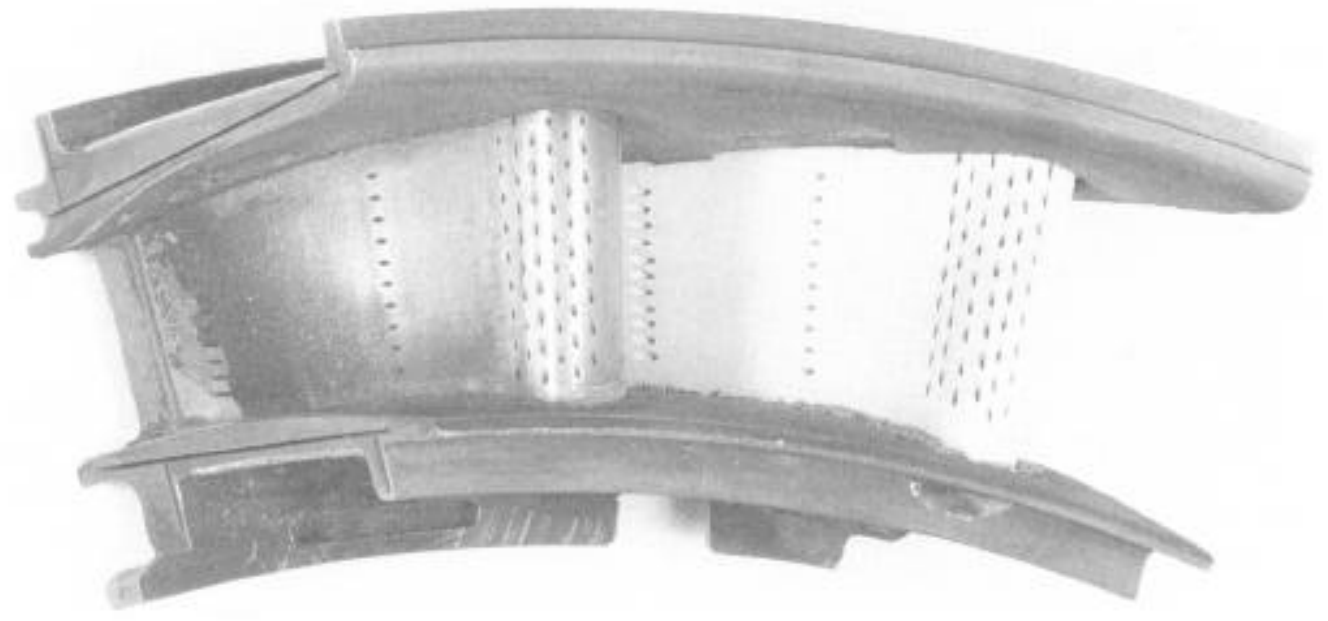

Figure 16. Fully manufactured HPT nozzle. Left vane is a single crystal NiAl alloy and right vane is a single crystal superalloy. 


\section{Component and Engine Tests}

During the manufacturing of the NiAl HPT vanes, several component tests were performed prior to the engine test. These tests addressed the Zoncern of thermal shock resistance because of the low ductility of the alloy, In addition, these tests served as proof tests' deemed necessary to weed out parts which might fail prematurely due to a manufacturing defect or handling damage. Component tests were also used to validate several new features utilized to design this vane. These component tests simulated engine thermal transient conditions as much as possible. Prior to an engine test, a full scale combustor rig test was successfully carried out. A fully assembled nozzle assembly is shown in Figure 17. In this assembly, the NiAl vanes were tested alongside single crystal superalloy vanes. After the engine test, no distress was observed in the NiAl vanes while the superalloy vanes showed some spallation of the thermal barnier coating.

The suceessful engine test of the HPT vane has demonstrated that it is possible to design, manufacture and engine test complicated turbine engine parts made out of limited ductility intermetallic alloys in highly stressed and harsh environments. In essence, technical feasibility of such materials has been demonstrated. However, production implementation will still be a difficult challenge primarily due to limited ductility and damage tolerance.

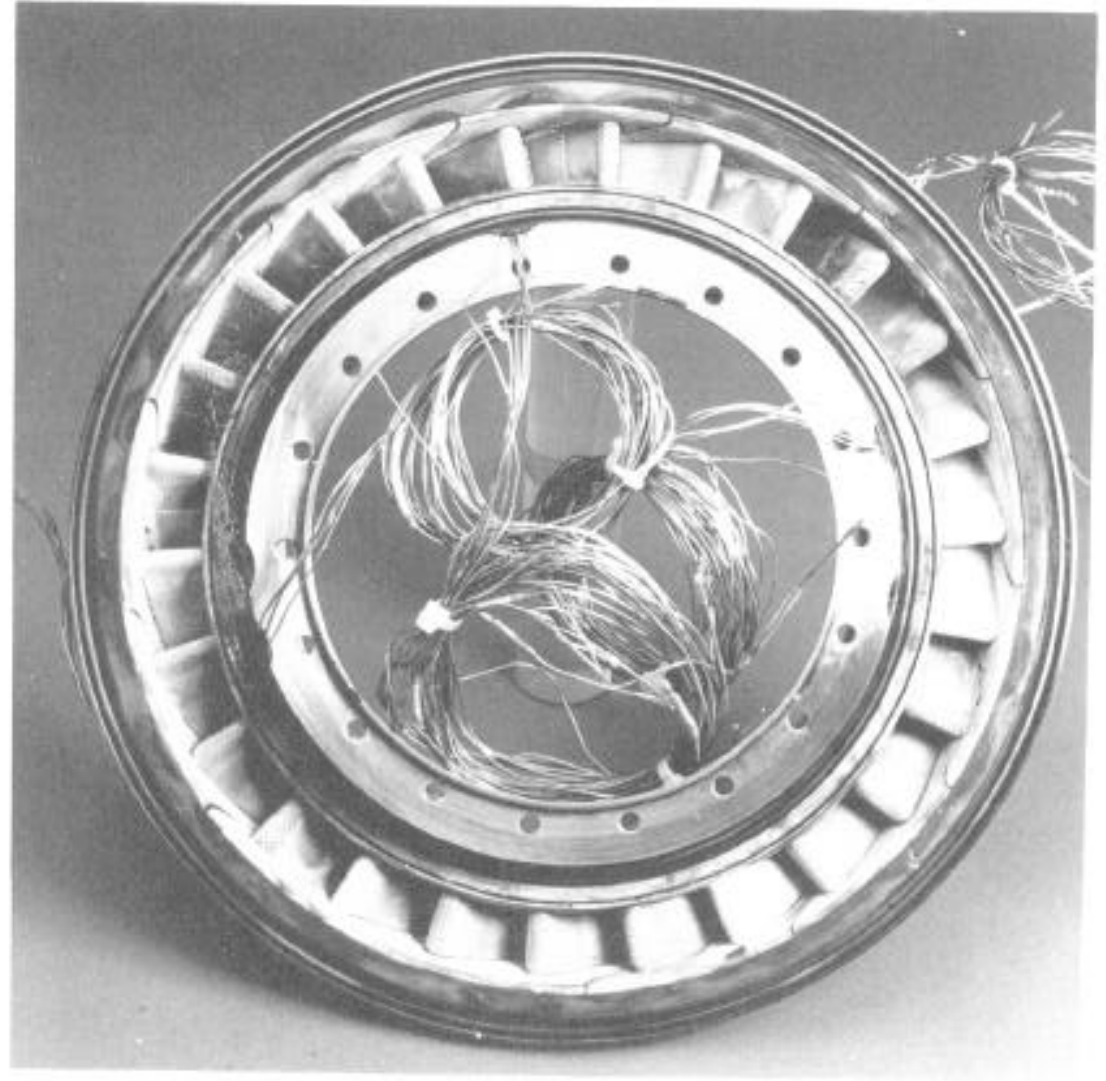

Figure 17. Fully assembled HPT nozzle containing NiAl alloy vanes.

\section{NiAl Matrix Composites as Alternatiyes to Single Crystal NiAl Alloys}

The single crystal alloys described in previous sections have exhibited very high creep strengths. However, these alloys are not very tough, and extensive design changes will be required to accommodate these low values. It is preferable to have materials that are both tough and creep resistant. Figure 18 displays both creep strength and toughness of various NiAl systems and compares them to approximate goals. This figure indicates that two composite strategies have potential for reaching a balance of strength and toughness.

NiAl based directionally solidified eutectics (DSE's) have shown some potential to reach an appropriate balance of properties. NiAl with $\alpha-\mathrm{Cr}$, $\alpha-\mathrm{Mo}$ or $\mathrm{Cr}-\mathrm{Mo}$ are two phase eutectics that have been extensively studied, ${ }^{[6]}$ and Oliver and co-workers ${ }^{[32,33]}$ have developed a threephase eutectic with both $\alpha$-Cr and the Ta-rich Laves phase co-existing. They have found that the $\alpha$-Mo and the Cr/Mo eutectic alloys are reasonably tough, and the Ta-rich Laves phase eutectics are very good in creep. The next step of progressing to the three-phase Laves plus $\alpha$ $\mathrm{Cr}$ showed a substantial gain in toughness at only a small sacrifice in creep strength. This indicates that further alloy development along this line has considerable potential for reaching the balanced creep/toughness goals. Transverse properties, thermal stability and expensive processing methods have limited the application of the past Ni-base superalloy eutectic alloys and NiAI based DSE's may have similar constraints. However. cost/benefit trude-offs can change over time, and NiAl DSE's may have cost advantages over competing ceramic composites.. A modest level of effort is appropriate to more fully explore the feasibility of achieving an appropriate balance of properties in these alloys.

Another promising alternative is provided by AIN strengthened NiAl, which is produced by high energy milling in liquid $\mathrm{N}_{2}$, a process termed cryomilling. ${ }^{[34]}$ Nitrogen is absorbed into the NiAl powders during cryomiling and forms high volume fractions of AIN in the form of 
nanometer sized particles. The most desirable microstructure obtained thus far has been obtained by hot extrusion, where the very fine nitride particles are clustered and strung out parallel to the extrusion axis. It is possible to vary the milling conditions to ohtain nitride contents ranging from 0 to 30 vol.\%. It has been found ${ }^{[35]}$ that improvements in creep resistance scaled with the volume fraction of AIN, yet room temperature fracture toughness was not affected by AIN content. This combination of properties is also displayed in Figure 18, where the cryomilled material showed equivalent creep strength and slightly better toughness compared to the single crystal NiAl alloys. Another advantage of the cryomilled material is its relatively low DBTT. Measurements of fracture toughness as a function of temperature, Figure 19, indicate that unalloyed $\mathrm{NiAl}$ has the lowest DBTT, achieving $20 \mathrm{ksi} \sqrt{\mathrm{in}}$ at about $750^{\circ} \mathrm{F}\left(400^{\circ} \mathrm{C}\right)$. The cryomilled NiAl +30 vol. $\%$ AlN exhibited a DBTT shift to about $1000^{\circ} \mathrm{F}\left(550^{\circ} \mathrm{C}\right)$, which is considerably lower than that seen in single crystal NiAl alloys. A DBTT of $1000^{\circ} \mathrm{F}$ is low enough that the entire turbine blade could be designed to be operated in the ductile regime, thus providing adequate toughness.

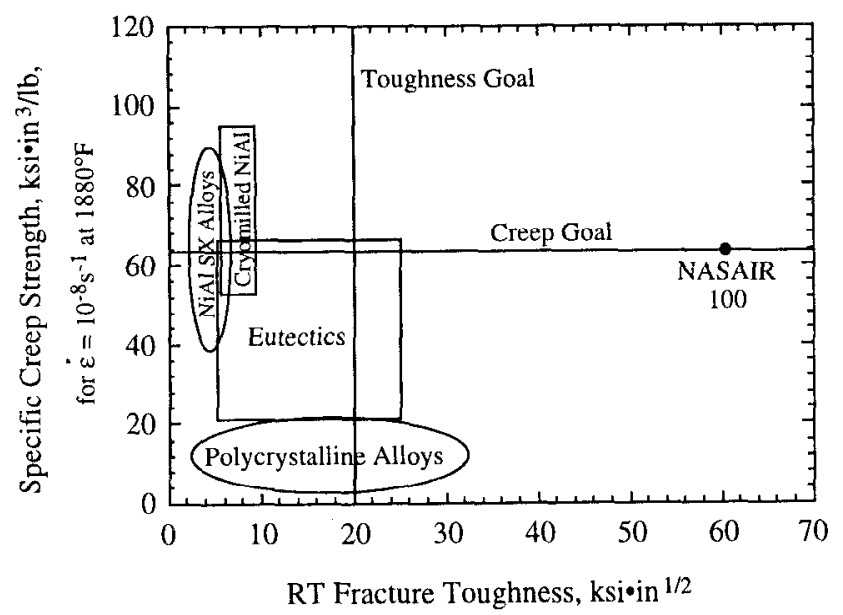

Figure 18. Creep/toughness plot showing typical ranges for different $\mathrm{NiAl}$ systems.

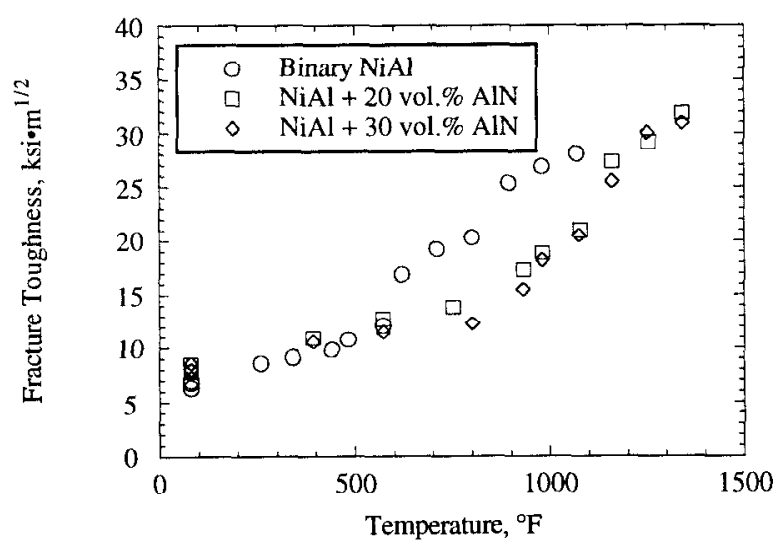

Figure 19. Fracture toughness of cryomilled NiAl containing AlN particles as a function of temperature.

\section{Summary}

Significant progress in material properties, processing, and design methodology has heen made for the NiAl technology. High strength $\mathrm{NiAl}$ alloys which compete with $\mathrm{Ni}$-base superalloys have been developed. Single crystal turbine airfoils with complex design features have been fabricated by a combination of casting and various machining processes. In addition, component and engine tests have been carried out successfully. However, low fracture toughness, poor impact resistance and high DBTT continue to be a concern when they are considered as replacements for ductile, high toughness $\mathrm{Ni}$-base superalloys.

Three generic problems exist for most high temperature intermetallics, and the alloy developer typically encounters at least two of them for a given intermetallic system:

1. Low ductility and toughness, especially at low temperatures.

2. A balance of sufficient creep strength, ductility and toughness.

3. Environmental stability.

For example, the first two items remain important issues for $\mathrm{NiAl}$ and for $\mathrm{MoSi}_{2}$, and all three still present various degrees of difficulties for $\mathrm{Nb}_{5} \mathrm{Si}_{3}$-based eutectics. ${ }^{[36,37]}$ As more experience is gained with these alloy systems, three conclusions emerge:

1. Ni-based superalloys are remarkably good materials with properties that are extremely difficult to surpass.

2. Any new material which is developed to replace superalloys will probably carry with it vestiges of one or more of the abovementioned three problems, and therefore:

3. Use of new intermetallic-based alloy systens will be very selective and gradual, and it is unlikely that there will be a rapid and widespread displacement of $\mathrm{Ni}$-based superalloys.

\section{Acknowledgments}

The authors gratefully acknowledge the support of their employers in this research over the past many years and also thank several US agencies for continuing support: the Air Force, the Air Force Office of Scientific Research, Navy and NASA.

\section{References}

1. R. Darolia, "NiAl Alloys for High Temperature Structural Applications", JQM, 43 (3) (1991), 44-49.

2. R. Darolia, D. F. Lahrman, R. D. Field, J. R. Dobbs, K. M. Chang, E. H. Goldman and D. G. Konitzer, "Overview of NiAl Alloys for High Temperature Structural Applications", Ordered Intermetallics - Physical Metallurgy and Mechanical Behavior, C. T. Liu, et al, eds., Vol. 213, (Kluwer Academic Publishers, Netherlands, 1992), 679-698.

3. R. Darolia, "NiAl for Turbine Airfoil Applications", Structural Intermetallics, R. Darolia, et al, eds., TMS, 1993, 495-504. 
4. D. B. Miracle, "The Physical and Mechanical Properties of NiAl", Acta metall mater, 41 (3) (1993), 649-684.

5. D. B. Miracle and R. Darolia, "NiAl and Its Alloys", Intermetallic Compounds: Principals and Practice, J. H. Westbrook, et al, eds., (John Wiley and Sons, New York, 1993), 53-72.

6. R. D. Noebe, R. R. Bowman and M. V. Nathal, "Review of the Physical and Mechanical Properties of the B2 Compound NiAl", Inter. Mater. Rey, 38 (4) (1993), 193-232.

7. W. S. Walston and R. Darolia, "Effect of Alloying on Physical Properties of NiAl", High-Temperature Ordered Intermetallics V, I. Baker, et al, eds., MRS, 1993, 237-242.

8. R. J. Wasilewski, "Elastic Constants and Young's Modulus of NiAl", Trans. AIME, 236 (1966), 455-457.

9. D. F. Lahrman, R. D. Field and R. Darolia, "The Effect of Strain Rate on the Mechanical Properties of Single Crystal NiAl", HighTemperature Ordered Intermetallics IV, L. Johnson, et al, eds., MRS, 1991, 603-607.

10. R. Darolia and W. S. Walston, "Effect of Specimen Surface Preparation on Room Temperature Tensile Ductility of a FeContaining NiAl Single Crystal Alloy", accepted for publication in Intermetallics, 1996.

11. D. R. Johnson, S. M. Joslin, B. F. Oliver, R. D. Noebe and J. D. Whittenberger, 1st Int. Conf. on Processing Materials for Properties, H. Henien, et al, eds., TMS, 1993, 865.

12. R. Darolia, D. Lahrman and R. Field, "The Effect of Iron, Gallium and Molybdenum on the Room Temperature Tensile Ductility of NiAl", Scr. Met. 26 (1992), 1007-1012.

13. R. J. Wasilewski, S. R. Butler and J. E. Hanlon, "Plastic Deformation of Single Crystal NiAl", Met. Soc.AIME, 239 (1967), 1357-1364.

14. R. Darolia, W. S. Walston and D. F. Lahrman, Unpublished Research, GE Aircraft Engines, 1992.

15. K. M. Chang, R. Darolia and H. A. Lipsitt, "Cleavage Fracture in B2 Aluminides", Acta Metall, 40 (1992), 2727-2737.

16. R. Darolia, K. M. Chang and J. E. Hack, "Observation of High Index \{511\} Type Fracture Planes and Their Influence on Toughness in NiAl Single Crystals", Intermetallics, 1 (1993), 65-78.

17. J. E. Hack, J. M. Brzeski, R. Darolia and R. D. Field, "Evidence of Inherent Ductility in Single Crystal NiAl", High-Temperature Ordered Intermetallics V, I. Baker, et al, eds., MRS, 1993, 1197. 1202.

18. R. Darolia, W. S. Walston, R. D. Noebe and M. Nathal, "Design Methodology for Intermetallics", F33615-94-C-2414, 1994-present

19. W. S. Walston, R. D. Field, J. R. Dobbs, D. F. Lahrman and R. Darolia, "Microstructure and High Temperature Strength of NiAl Alloys", Structural Intermetallics, R. Darolia, et al, eds., TMS, 1993, 523-532.

20. M. Rudy and G. Sauthoff, "Dislocation Creep in the Ordered Intermetallic (Fe,Ni)Al Phase", Mat. Sci. and Eng, 81 (1986), 525 530.

21. M. Rudy and G. Sautoff, "Creep Behavior of the Ordered Intermetallic ( $\mathrm{Fe}, \mathrm{Ni}) \mathrm{Al}$ Phase", High-Temperature Ordered Intermetallics, C. C. Koch, et al, eds., MRS, 1989, 327-333.
22. G. Sauthoff, "Intermetallic Phases - Materials Developments and Prospects", Z. Metallkde, 80 (1989), 337-343.

23. R. S. Polvani, W. Tzeng and P. R. Strutt, "High Temperature Creep in a Semi-Coherent NiAl-Ni2AITi Alloy", Metall Trans, 7A (1976), 33-40.

24. I. E. Locci, R. D. Noebe, R. R. Bowman, R. V. Miner, M. V. Nathal and R. Darolia, "Microstructure and Mechanical Properties of a Single Crystal NiAl Alloy with Zr or Hf-rich G-phase Precipitates", High-Temperature Ordered Intermetallics IV, L. A. Johnson, et al, eds., MRS, 1991, 1013-1018.

25. I. E. Locci, R. Dickerson, R. R. Bowman, J. D. Whittenberger, M. V. Nathal and R. Darolia. "Microstructure and Mechanical Properties of Cast, Homogenized and Aged NiAl Single Crystal Containing Hf", High-Temperature Ordered Intermetallics V, I. Baker, et al, eds., MRS, 1993, 685-690.

26. A. Garg, R. D. Noebe and R. Darolia, "Crystallography of the NiHfSi Phase in a NiAl (0.5 Hf) Single Crystal Alloy", accepted for publication in Acta Metall, 1995.

27. W. D. Nix and R. H. Dauskardt, "High Temperature Deformation and Fracture Resistance of Single Crystals of $\mathrm{NiAl}$ and NiAl-Based Intermetallic Alloys", (Stanford University, Annual Technical Report, AFOSR AF-F49620-95-1-0163, 1995).

28. E. H. Goldman, "Single Crystal Processing of Intermetallics for Structural Applications", High-Temperature Ordered Intermetallics V, I. Baker, et al, eds., MRS, 1993, 83-94.

29. E. H. Goldman, "Advanced NiAl Turbine Blade", (GE Aircraft Engines, F33615-90-C-5938, Interim Report, 1992).

30. T. J. Moore and J. M. Kalinowski, U.S. Patent 5,284,290.

31. R. D. Noebe, A. Garg, D. Hull, J. Kalinowski, R. Darolia and W. S. Walston, "Joining of NiAl to Ni-Base Superalloys", HITEMP Review, NASA CR-10178, 1995, 29-1 to 29-20.

32. D. R. Johnson, X. F. Chen, B. F. Oliver, R. D. Noebe and J. D. Whittenberger, "Processing and Mechanical Properties of In-situ Composites from the NiAl-Cr and the NiAl-(Cr,Mo) Eutectic Systerns", Intermetallics, 3 (1995), 99-113.

33. D. R. Johnson, X. F. Chen, B. F. Oliver, R. D. Noebe and J. D. Whittenberger, "Directional Solidification and Mechanical Properties of NiAl-NiAlTa Alloys", Intermetallics, 3 (1995), 141 152.

34. J. D. Whittenberger, "Characteristics of an Elevated Temperature AlN Particulate Reinforced NiAl", Structural Intermetallics, $\mathbf{R}$. Darolia, et al, eds., TMS, 1993, 819-828.

35. M. G. Hebsur, I D. Whittenterger, C. E. Lowell and A. Garg, "NiAl-Base Composite Containing High Volume Fraction of AlN Particulate for Advanced Engines", High-Temperature Ordered Intermetallic Alloys VI, J. A. Horton, et al, eds., MRS, 1995, 579. 584.

36. M. R. Jackson, B. P. Bewlay, R. G. Rowe, D. W. Skelly and H. A. Lipsett, "High-Temperature Refractory Metal-Intermetallic Composites", JOM, 48 (1) (1996), 39-44.

37. P. R. Subramanian, M. G. Mendiratta and D. M. Dimiduk, "The Development of $\mathrm{Nb}$-Based Advanced Intermetallic Alloys for Structural Applications", JOM, 48 (1) (1996), 33-38. 